\title{
Interlaminar Strength Analysis of Bonded Carbon Fiber Rods
}

\author{
Tomas VAITKŪNAS*, Paulius GRIŠKEVIČIUS**, Kęstutis ŠPAKAUSKAS*** \\ *Kaunas University of Technology, Studentu g. 56, 51424 Kaunas, Lithuania, E-mail: tomas.vaitkunas@ktu.lt \\ **Kaunas University of Technology, Studentu g. 56, 51424 Kaunas, Lithuania, E-mail: paulius.griskevicius@ktu.lt \\ ***Kaunas University of Technology, Studentu g. 56, 51424 Kaunas, Lithuania, E-mail: kestutis.spakauskas@ktu.lt \\ crossref http://dx.doi.org/10.5755/j02.mech.25872
}

\section{Introduction}

Carbon and glass fiber reinforced polymer composites (CFRP and GFRP) are one of the best choices for lightweight high strength constructions suitable to aerospace, aviation, marine, automotive, sports applications [1]. In order to make CFRP and CFRP constructions strong enough for multidirectional loading: tension-compression, shear forces, bending and twisting moments, their elements are combined of different composite materials and layers, oriented at different angles. Composite construction designed to be loaded by bending moments and transverse forces is usually made as an I-beam (Fig. 1) which has outer CFRP or GFRP layers, bonded with low density foam core or GFRP wall. There are a lot of constructions where CFRP or GFRP layers are made of bonded carbon or glass fiber rods. Several examples of these constructions are given in Fig. 1 [2, 3].
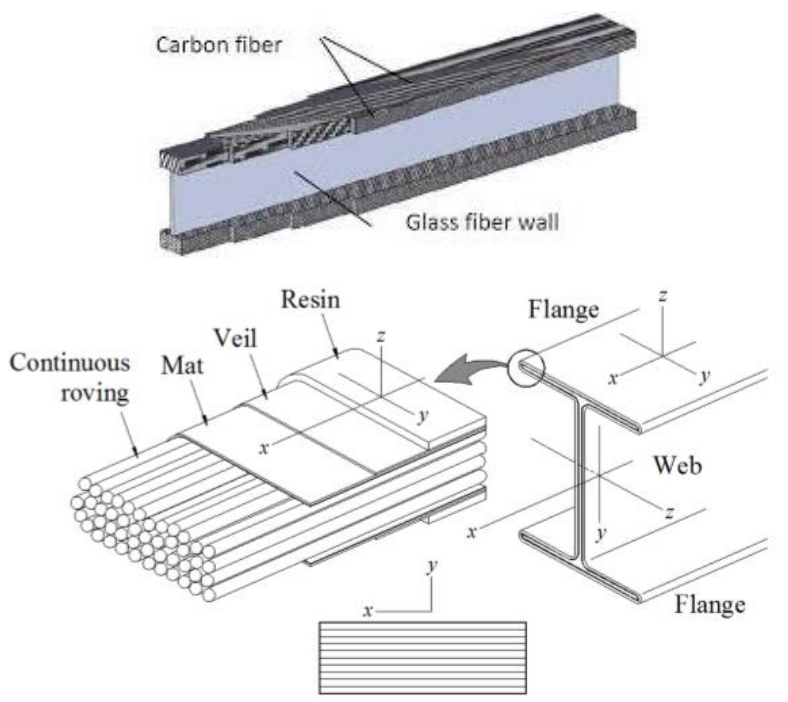

Fig. 1 Examples of composite constructions with CFRP and GFRP rods [2, 3]

In Fig. 1 top glider LAK 17A construction with CFRP rods is shown [2]. Below the scheme of composite beam with GFRP rods [3] is explained. CFRP layers of these constructions resist deformations caused by bending moments while core and GRFP layers, oriented at $\pm 45^{\circ}$, shear forces loading.

Interlaminar failure is very common in bonded polymer composite structures. Bending moments cause different axial strains and stresses of the CFRP or GFRP rods. The highest strain and stress is seen in the outer rods of the beam in respect to the neutral layer while the lowest strain and stress occurs in inner rods. Thus delamination between bonded rods can be expected. In order to ensure the safety of reliable composite constructions, their strength evaluation is crucial. Today finite element models (FEM) are very promising composite construction evaluation alternative to experimental testing. Reliable validated by experiments FEM can help to reduce or completely refuse expensive experimental testing procedures to estimate a composite construction. This can slightly reduce time spent to design a composite construction too.

The necessity of good knowledge about interlaminar failure mechanisms is important to create a reliable FEM of the composite structure. The aim of this study is to analyze the interlaminar strength of bonded carbon fiber rods used in composite I-beams. There are several tasks included to perform the analysis: 1. to review analytic equations describing overall delamination process; 2 . to perform interlaminar strength experiments of bonded carbon fiber rods; 3 . to create FEM of bonded carbon fiber rods, validated by these experiments; 4 . to model experiment specimen by performing a new numerical method peridynamics. All of these tasks could help to better understand the interlaminar behaviour of polymer composite constructions and create more accurate their FEM.

\section{Analytic delamination process analysis}

There are three different interlaminar failure modes (Fig. 2) [4]. I mode related to the tension of bonded parts, mode II - with shear when parts are sliding to each other's surface and III - with scissoring of the parts.

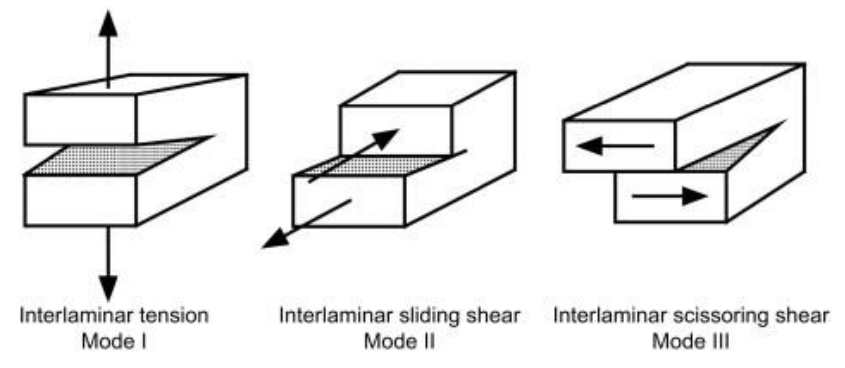

Fig. 2 Interlaminar failure modes [4]

Most of these composite constructions are beams loaded by shear forces and bending moments while twisting moments are slightly lower. Thus failure modes I and II are expected mostly and mode III is uncommon.

Energy release rate $G$ is related to the change of deformation energy $d U$ and the increase of delamination length $d a$ by equation [5]:

$$
G=-\frac{1}{b} \cdot \frac{d U}{d a}
$$


where: $b$ is the width of the specimen.

A very important parameter in interlaminar processes is fracture toughness $G_{C}$. Energy release rate $G$ in mode I delamination can be expressed by using external load $P$ acting as shown in Fig. 2.

$$
G_{I}=\frac{3 P \delta}{2 b a}
$$

where: $\delta$ is displacement. Maximum energy release rate in mode II delamination is related to external load by [6]:

$$
G_{I I}=\frac{9 P_{\max } a_{0}{ }^{2} \delta}{2 b\left(\frac{L^{2}}{4}+3 a_{0}{ }^{2}\right)},
$$

where: $a_{0}$ is the initial crack length of the specimen; $L-$ length between support and loading point of the specimen.

A lot of different laws are used to analytically describe the interlaminar processes [7]: linear, bilinear, multilinear, linear-exponential (Fig. 3).

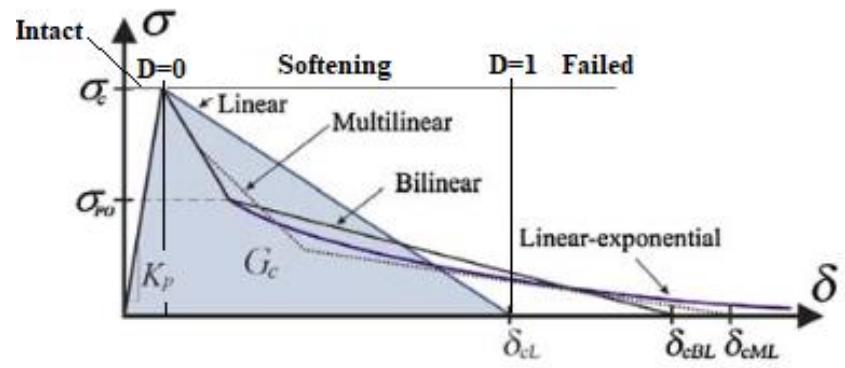

Fig. 3 Interlaminar process approximation methods [7]

Mostly used in FEM or analytic calculations and the simplest is a linear approximation. When maximum stress $\sigma_{c}$ is achieved, softening occurs. Damage grows from 0 to 1 when displacement is $\delta_{c L}$. Fracture toughness is known as work necessary to achieve interlaminar failure and expressed as the area between abscises axis and curve.

As it was mentioned before, modes I and II are expected mostly in composite beams. In order to evaluate failure and damage, caused by mixed I and II mode delamination process, several criteria are used. The following simple linear interaction criterion has been suggested, when $\alpha=\beta=1$ :

$$
\left(\frac{G_{I}}{G_{I c}}\right)^{\alpha}+\left(\frac{G_{I I}}{G_{I I c}}\right)^{\beta}=1 .
$$

Today in FEM calculations more often Benzeggagh and Kenane criterion is used:

$$
G_{c}=G_{I c}+\left(G_{I I}-G_{I c}\right)\left(\frac{G_{I I}}{G_{T}}\right)^{\eta},
$$

where: $\eta$ is exponent power. The parameters $G_{I c}, G_{I I c}$, and $\eta$ are required input to perform a FEM analysis in current commercial implementations, such as Ansys, Nastran, Abaqus.

Interlaminar bond failure of sandwich structure composite beam, loaded with transverse force, can be found by evaluating the fracture toughness $G_{c}[8]$ :

$$
P \geq \frac{B_{3} b t c}{l} \sqrt{\frac{G_{C} E}{t}},
$$

where: $E$ is modulus of elasticity of CFRP rods in the fiber direction; $B_{3}$ is coefficient which depends on boundary conditions [8]. The most critical is composite cantilever beam loaded with concentrated force $\left(B_{3}=1\right)$ and at least critical 3-point bending of the beam with acting distributed load $\left(B_{3}=12\right)$. Other parameters of equation (6) are given in Fig. 4 [8].

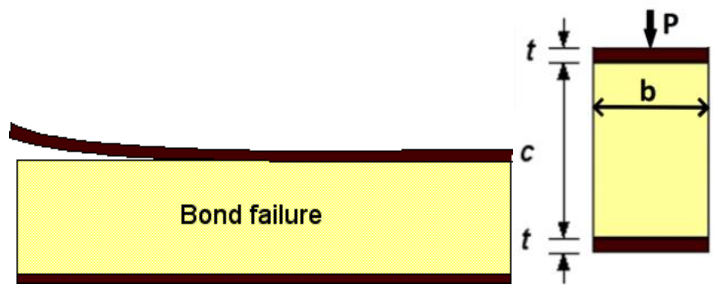

Fig. 4 Bond failure of the composite beam [8]

Eq. (6) shows possible composite beam interlaminar failure. Mode I and II fracture toughness are very important in interlaminar failure evaluation analytically (Eq. (6)) and by using FEM. According to this fact, delamination experiments of carbon fiber rods of composite structures were performed and fracture toughness found.

\section{Experimental testing}

In order to find interlaminar failure mode I fracture toughness, several specimens were made according to the standard ASTM D 5528 [5]. Also, other standards, such as ASTM D 907, ASTM D 2093 for surface bonding [9- 10] and ISO 291 for experiment environment conditions [11], were applied.

Specimens were made by using hinges $40 \times 57 \times 0.75 \mathrm{~mm}$ and square carbon fiber rods Graphlite SM315 3x3 mm bonding them with resin CR83 with hardener CH83-2. The length of carbon fiber rods is $130 \mathrm{~mm}$ and the bond length $80 \mathrm{~mm}$ (initial delamination length $a_{0}=50 \mathrm{~mm}$ ). Specimen photo during the experiment is shown in Fig. 5.

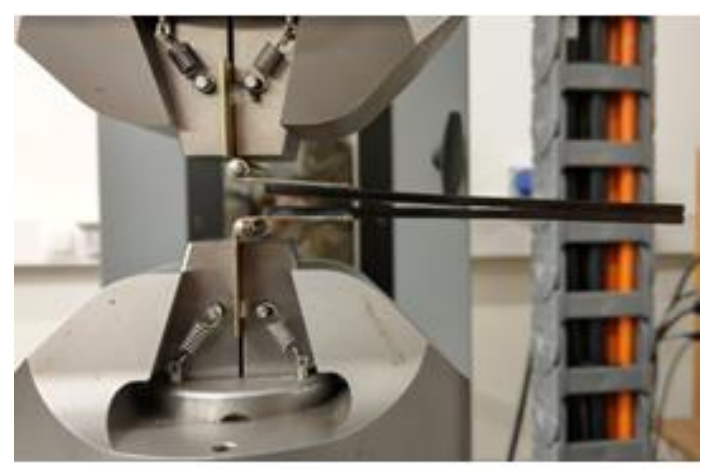

Fig. 5 Mode I interlaminar failure specimen of carbon fiber rods

The strength tests of bonded carbon fiber rods were performed on an Instron E10000 electromechanical 
test machine with software BlueHill. The speed of deformation was selected $3 \mathrm{~mm} / \mathrm{min}$. To capture delamination growth high speed video camera Phantom V2511 was used and delamination length measured with software DICe. An experimental setup is shown in Fig. 6

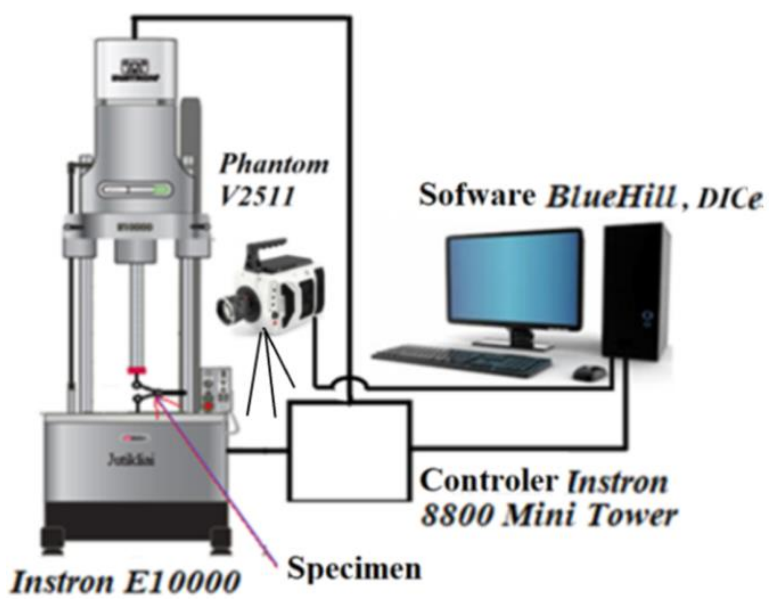

Fig. 6 Experimental setup

\section{Testing results}

Force-displacement curves of static strength tests are given in Fig. 7. Several curves of different specimens are given to demonstrate the dispersion of experiment results.

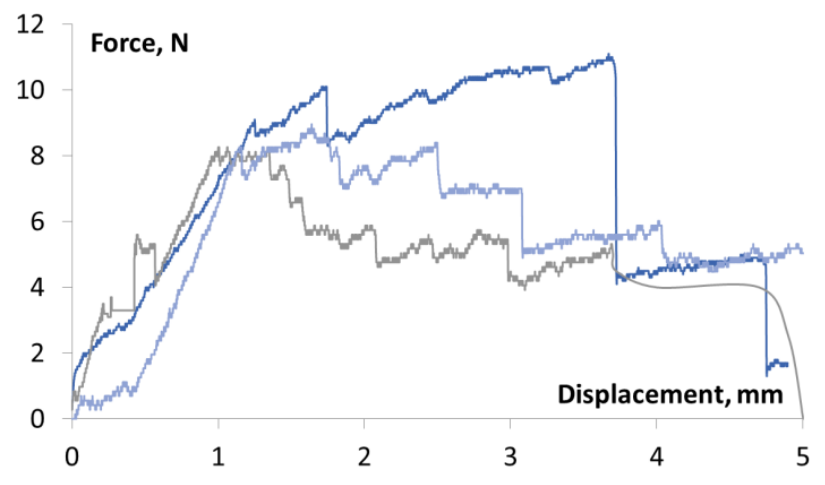

Fig. 7 Force-displacement curves of specimens

Maximum interlaminar failure force is not higher than 11 N. Sudden jumps of the force of some specimens can be explained by high stiffness of the rods which make delamination crack growth process unstable.

Interlaminar toughness of specimens is shown in Fig. 8. Here $G_{I C}$ dependency on delamination length, also known as R-curve, given.

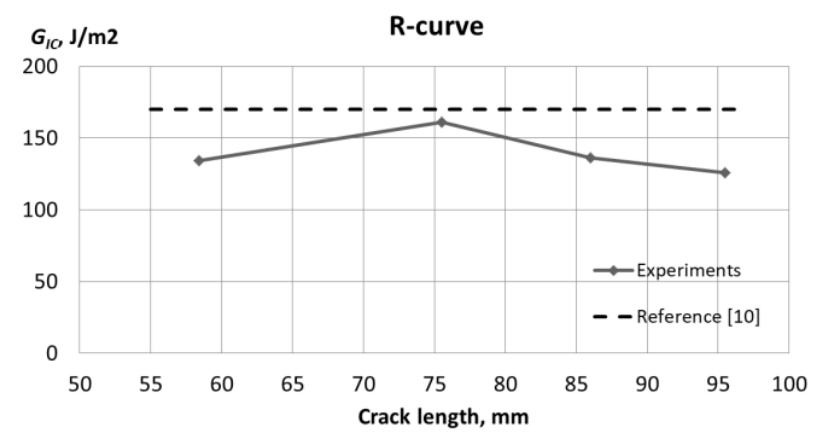

Fig. 8 R-curve of bonded carbon fiber rods
In Fig. 8 upper curve shows a fracture toughness value of CFRP composite bonded with epoxy resin $G_{I C}=160-180 \mathrm{~J} / \mathrm{m}^{2}$ given in reference [4]. During the interlaminar strength tests of carbon fiber rods fracture toughness value $G_{I C}=135 \mathrm{~J} / \mathrm{m}^{2}$ was found.

Modelling interlaminar behavior of composite structures requires to known fracture toughness value $G_{I I C}$ of interlaminar failure mode II too. $G_{I I C}$ can be found the same way by performing an experiment with specimens prepared according to the standard ASTM D 7905. Although experimental testing is reliable, it is expensive and time consuming. Time for testing in the commercial environment of the companies is almost always limited. Thus faster and easier methods are preferred to find $G_{I I C}$. Relation laws between failure modes I, II and damage, caused by this failure, can be used.

In this study $G_{I I C}$ for bonded carbon fiber rods calculated according to Benzeggagh and Kenane criterion and experiments results of CFRP composites bonded with epoxy resin [4]. These results are given in Fig. 9.

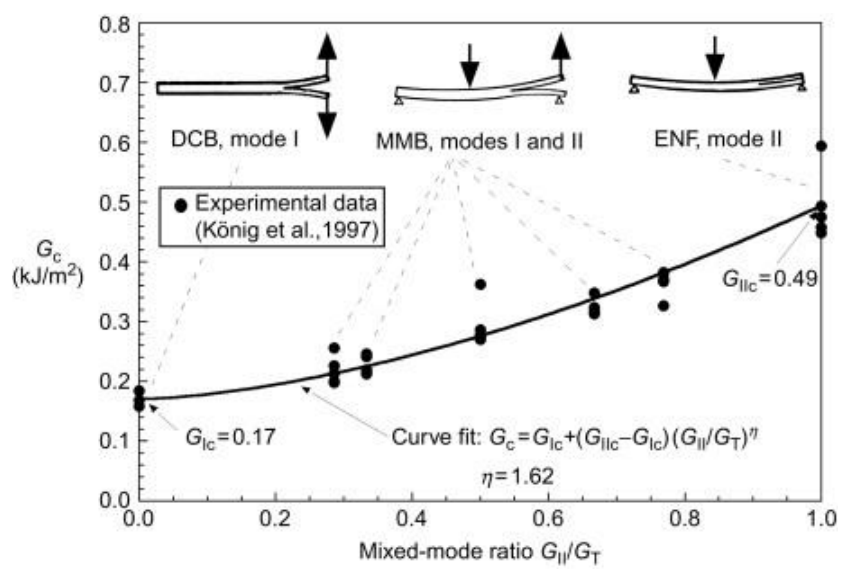

Fig. 9 Relation between modes I and II according to the Benzeggagh and Kenane criterion [4]

When $G_{I C}=170 \mathrm{~J} / \mathrm{m}^{2}, G_{I I C}$ is equal to $490 \mathrm{~J} / \mathrm{m}^{2}$. Exponent power for carbon fiber is $\eta=1.62$. Having data from our I mode interlaminar failure experiment and Fig. 9 [4], also using Benzeggagh and Kenane criterion equation (5) we can calculate $G_{I I C}$ for bonded carbon fiber rods, $G_{I I C}=400 \mathrm{~J} / \mathrm{m}^{2}$. The values of carbon fiber bonded rods $G_{I C}=135 \mathrm{~J} / \mathrm{m}^{2}, G_{I I C}=400 \mathrm{~J} / \mathrm{m}^{2}$ and $\eta=1.62$ are very useful for creating FEM of composite beam type constructions with bonded carbon fiber rods.

\section{Finite element modelling}

Software $L S$-Dyna was selected to create FEM of interlaminar failure mode I specimen. Geometry was modelled by using LS-Prepost 4.6. This created model can be easily solved by other software, such as Ansys, and that makes the model more useful. 4 nodes SHELL type finite elements were used for modelling carbon fiber rods. According to the recommendations of LS-Dyna manual for modelling composites [12], material type *MAT_054: ENHANCED_COMPOSITE_DAMAGE was used. Material properties of CFRP rods were used according to the [13] and given in Table 1.

Chang-Chang criterion selected to consider material failure. Boundary conditions of the specimen in FEM were chosen to be close to real experimental conditions. 
The end of the specimen was fixed only by allowing rotation around and movement to the longitudinal axis of the hinge. This imitates constraint of the hinges. Also, at points where rods are contacting with the hinge, rotation about hinge axis and movement to the longitudinal axis of the hinge were constrained. The constraint, created by the bonds between rods and hinges, was imitated here.

Table 1

CFRP rods mechanical properties [13]

\begin{tabular}{|l|l|}
\hline Young modulus in the fiber direction, GPa & 81 \\
\hline Young modulus transversely to the fiber, GPa & 20 \\
\hline Poisson's ratio & 0.067 \\
\hline Shear modulus in the fiber direction, GPa & 15 \\
\hline Shear modulus transversely to the fiber, GPa & 15 \\
\hline Shear modulus transversely to the fiber plane, GPa & 15 \\
\hline $\begin{array}{l}\text { Compressive strength limit in the fiber direction, } \\
\text { MPa }\end{array}$ & 841 \\
\hline Tensile strength limit in the fiber direction, MPa & 1080 \\
\hline $\begin{array}{l}\text { Compressive strength limit transversely to the fi- } \\
\text { ber, MPa }\end{array}$ & 841 \\
\hline Tensile strength limit transversely to the fiber, MPa & 100 \\
\hline Shear strength limit, MPa & 280 \\
\hline Maximum fiber tensile deformation & 0.02 \\
\hline Maximum fiber compressive deformation & -0.018 \\
\hline Maximum matrix deformation & 0.02 \\
\hline
\end{tabular}

A bonded joint between rods in software $L S$-Dyna can be modelled two ways: by using cohesive elements with material *MAT_138: COHESIVE_MIXED_MODE or contact AUTOMATIC_ONE_WAY_SURFACE_TO_ SURFACE_TIEBREAK. Parameters, used in contact modelling, were fracture toughness $G_{I C}=135 \mathrm{~J} / \mathrm{m}^{2}$, $G_{I I C}=400 \mathrm{~J} / \mathrm{m}^{2}$, exponent power $\eta=1.62$ and resin CR83 failure stress $80 \mathrm{MPa}$. Additionally, modelling contact with *CONTACT_TIEBREAK option normal stiffness CN of this contact must be specified. By the method of trials and errors, $\mathrm{CN}$ was set to $3 \cdot 10^{13} \mathrm{~N} / \mathrm{m}$ as giving the best coincidence between numerical and experimental results.

Despite that both methods are similar, the method with contact is simpler while cohesive elements can give smoother results. In order to compare results, simulations with both type bonds modelling options were done. Simulations' results are presented in Figs. 10 - 12 .

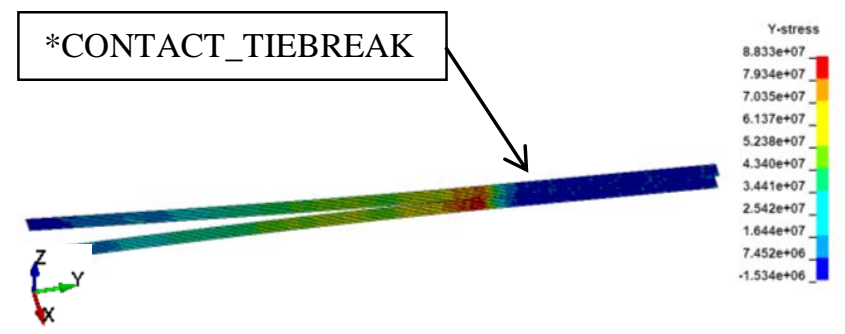

Fig. 10 Normal $\mathrm{Y}$ axis stress distribution in the top of interlaminar failure mode I specimen using *CONTACT_TIEBREAK option

Figs. 10 and 11 show the normal $\mathrm{Y}$ axis stress distribution in the top of specimen and Fig. 12 - simulated interlaminar force compared to the experimental average. The simulated force-displacement curve with *CONTACT_TIEBREAK shows almost the same strength and approximately 1.28 times bigger stiffness of the bond in comparison to cohesive elements. Maximum stress val- ue with *CONTACT - TIEBREAK is $91 \mathrm{MPa}$ and with cohesive elements $88 \mathrm{MPa}$. It is difficult to predict which model is more reliable, but simulated force-displacement curve with *CONTACT_TIEBREAK option is closer to the experimental average curve while delamination growth with cohesive elements is less stable. Differences between curves in Fig. 12 are not high and both models can be validated for estimating the interlaminar behavior of responsible composite constructions.
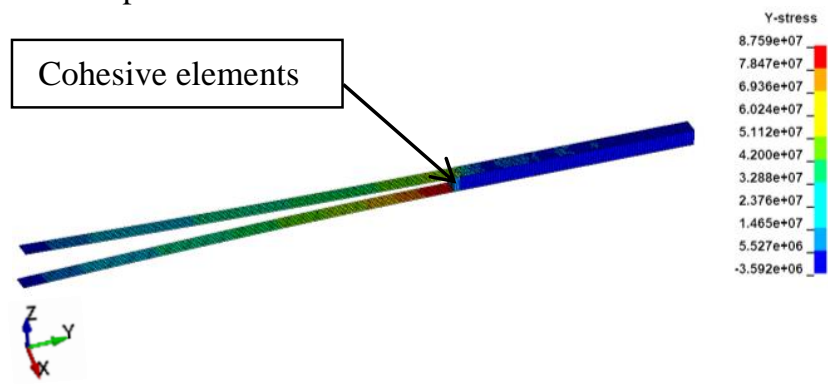

Fig. 11 Normal $\mathrm{Y}$ axis stress distribution in the top of interlaminar failure mode I specimen using cohesive elements

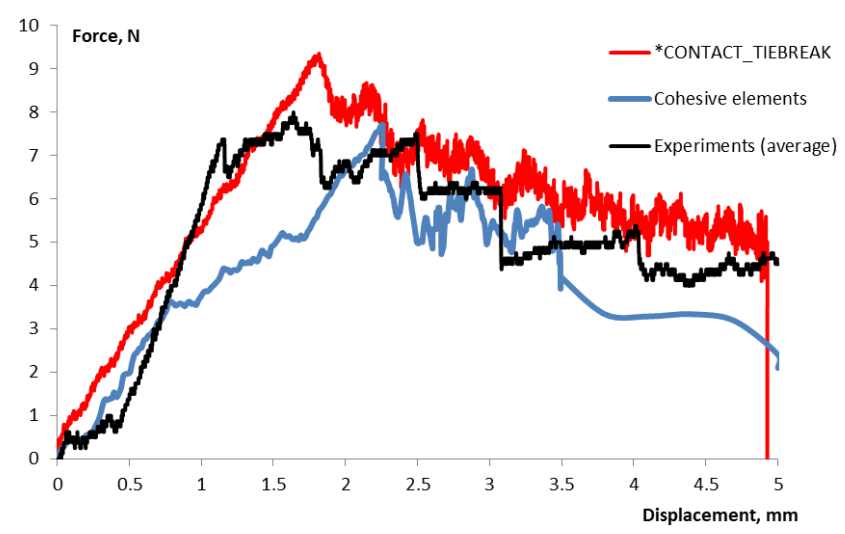

Fig. 12 Force-displacement curves of specimen

It is much simpler to use contact AUTOMATIC_ONE_WAY_SURFACE_TO_SURFA CE_TIEBREAK for models of complex composite structures than cohesive elements option. Also, attention should be paid at selecting $\mathrm{CN}$ values of the contact.

\section{Alternative numerical method: peridynamics}

Peridynamics is a mathematical theory of mechanics which extends the classical continuum mechanics by including cracks and discontinuities of material. Equation of peridynamics at each material point is expressed as:

$$
\rho \ddot{\boldsymbol{u}}(\boldsymbol{x}, t)=\int_{H_{x}} \boldsymbol{f}\left(\boldsymbol{u}, \boldsymbol{u}^{\prime}, \boldsymbol{x}, \boldsymbol{x}^{\prime}, t\right) d V_{x}+\boldsymbol{b}(\boldsymbol{x}, t),
$$

where: $\rho$ is the density of the material; $\boldsymbol{u}$ and $\boldsymbol{u}$ ' are displacements of material points $\boldsymbol{x}$ and $\boldsymbol{x}$, respectively. The volume of material point $\boldsymbol{x}^{\prime}$ is $V_{x^{\prime}} ; H_{x}$ - interaction range, called the horizon of the material point $\boldsymbol{x}$ and defined by radius $\delta ; \boldsymbol{b}$ is the external force density. Vector $\boldsymbol{f}$ represents the peridynamic force between the bonds [15]. Peridynamics equations do not include partial derivatives of coordinates and that makes peridynamics well suitable for structures with cracks and discontinuities analysis.

The composite peridynamics consists of two types 
of bonds, as shown in Fig. 13 [15]. The matrix bonds are oriented to all directions and show the mechanical properties of the resin. Fiber bonds are related to the mechanical properties of the fiber and are oriented only to the fiber direction.

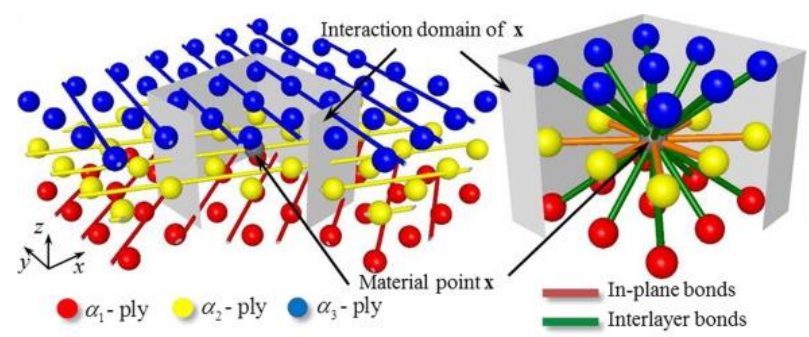

Fig. 13 Illustration of composite peridynamics: points, bonds and horizon [15]

The length of the bonds is usually selected about three increments of coordinates of the point to make the peridynamical model (PDM) stable and achieve accuracy of the results.

Software LS-Dyna is capable to calculate material with peridynamic properties. MAT_ELASTIC_PERI_ LAMINATE is the only one peridynamical material model of the composite, available in LS-Dyna. This material type includes an elastic material, a single layer composite. Due to poor selection of material with properties of peridynamics, PDM of the bond of the interlaminar failure mode I specimen was created manually by using MASS elements for points and BEAM - for peridynamic bonds. Material MAT_PLASTIC_KINEMATIC was selected and the parameter $\beta$ was set to 1 to eliminate the kinematic hardening effect. Cross section area of the beam is calculated according to the number of elements and bond area. Failure is characterized by the failure strain of the beam equal to 0.02 . Interlayer damage in terms of peridynamics is expressed as [14]:

$$
\begin{gathered}
\phi_{\text {Int_upper }}=1-\frac{\sum_{j=1}^{N_{i}^{\text {Int_upper }}}}{\mu_{i j}\left(\mathrm{x}, \mathrm{x}^{\prime}, t\right)} N_{i}^{\text {Int_upper }}, \\
\phi_{\text {Int_lower }}=1-\frac{\sum_{j=1}^{N_{i}^{\text {Int_lower }}} \mu_{i j}\left(\mathrm{x}, \mathrm{x}^{\prime}, t\right)}{N_{i}^{\text {Int_lower }}},
\end{gathered}
$$

where: $\mu$ is the status variable [14]. The damage is defined by a value between 0 and 1 , where 0 indicates that a material point has no damage and 1 indicates complete damage at this point.

The scheme of created PDM of interlaminar failure mode I specimen according to the [15] is shown in Fig. 14. As results of created PDM of CFRP rods, interlaminar failure mode I specimen stresses are shown in Fig. 15.

The maximum value of interlaminar stress $129 \mathrm{MPa}$, seen on Fig 14, is comparable to the bond strength $80 \mathrm{MPa}$. The calculated maximum force is $13 \mathrm{~N}$ while given by the previous simulations of traditional FEM is approximately less than $10 \mathrm{~N}$.

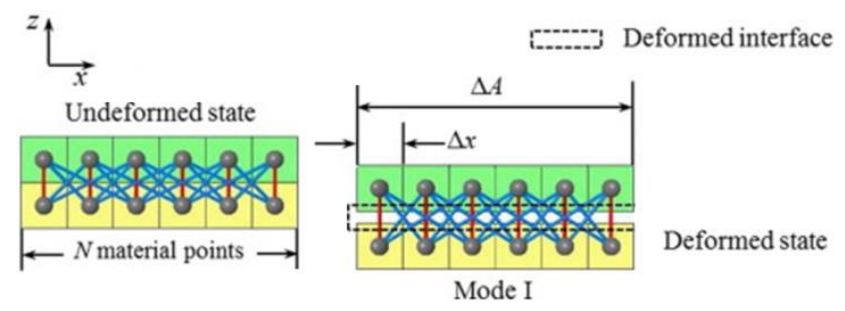

Fig. 14 Scheme of peridynamics of mode I loading [15]

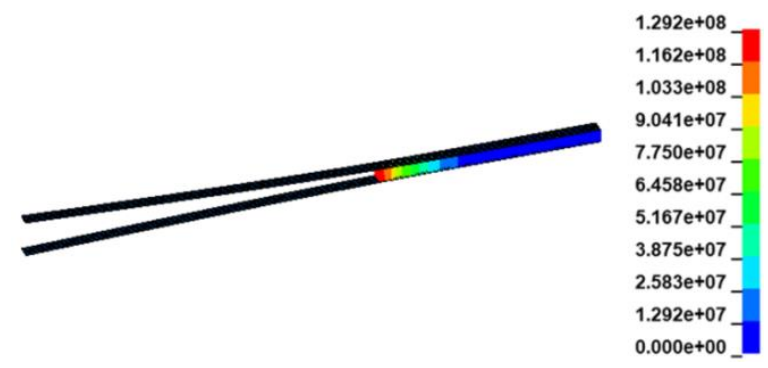

Fig. 15 Results of peridynamics: interlaminar stresses

Maximum interlaminar force of PDM is quite close to traditional FEM and experiments. Stress differences are possible at the boundaries of cohesion zone due to not full horizon of peridynamics. Also, our PDM can be improved by setting up the best size of the element. This could make the maximum value of interlaminar stress closer to $80 \mathrm{MPa}$ in the PDM. Despite peridynamics advantages analyzing structures with discontinuities, PDM is more difficult to create, requires more than 10 times higher number of finite elements and time to solve. In our opinion, it is a valid alternative FEM for small areas to analyse stress concertation, crack growth, interlaminar failure processes to check results of conventional FEM models.

\section{Conclusions}

Analytical, experimental and numerical interlaminar failure analysis of bonded carbon fiber rods was done in this study. The results showed several facts.

1. Mostly used in analytical calculations and FEM is linear delamination process approximation with Benzeggagh and Kenane failure criterion. It has a good agreement to experimental data [4].

2. After interlaminar mode I experiments were performed, fracture toughness of bonded CFRP rods is found $G_{I C}=135 \mathrm{~J} / \mathrm{m}^{2}$. Fracture toughness of mode II delamination found by using Benzeggagh and Kenane criterion and $G_{I C}$ value. According to the results given in [4] $G_{I I C}=400 \mathrm{~J} / \mathrm{m}^{2}(\eta=1.62)$.

3. Good agreement between experimental and simulated force-displacement curves confirms that model with material type ENHANCED_COMPOSITE_ DAMAGE and cohesive elements or *CONTACT_ TIEBREAK can be validated for modelling interlaminar behaviour of reliable GFRP and CFRP constructions.

4. Peridynamical methods are the best candidates for small areas of stress concentration, interlaminar failure or crack growth analysis.

\section{Acknowledgment}

This research is supported by Research Council of Lithuania (Project CompExSHM No.: P-MIP-19-523). 


\section{References}

1. Darshil, U. S. 2014. Natural fiber composites: Comprehensive Ashby-type materials selection charts, Materials \& Design (1980-2015) 62: 21-31. https://doi.org/10.1016/j.matdes.2014.05.002.

2. Gudeliauskas, R.; Lendraitis, M.; Manikanta, N. 2018. Strength and durability of carbon fiber bars adhesive bonding, Mechanika 24(3): 36-40.

https://www.researchgate.net/project/Strength-anddurability-of-carbon-fiber-bars-adhesive-bonding.

3. Landesmanna, A.; Serutia, C. A.; Batistaa, E. M. 2015. Mechanical properties of glass fiber reinforced polymers members for structural applications, Materials Research 18(6): 1372-1383.

http://www.scielo.br/scielo.php?script=sci_arttext\&pid $=$ S1516-14392015000601372.

4. Krueger, R. 2015. 1 - The virtual crack closure technique for modeling interlaminar failure and delamination in advanced composite materials, Numerical Modelling of Failure in Advanced Composite Materials: 353. https://doi.org/10.1016/B978-0-08-100332-9.00001-3.

5. ASTM D 5528. 2013. Standard Test Method for Mode I Interlaminar Fracture Toughness of Unidirectional Fiber-Reinforced Polymer Matrix Composites, ASTM International, West Conshohocken.

http://www.sophiahightech.com/astm-d-5528-testingfixture/.

6. ASTM D 7905. 2019. Standard Test Method for Determination of the Mode II Interlaminar Fracture Toughness of Unidirectional Fiber-Reinforced Polymer Matrix Composites, ASTM International, West Conshohocken.

7. Carlos, G. D.; Cheryl, A. R.; Camanho, P. P. 2009. A procedure for superposing linear cohesive laws to represent multiple damage mechanisms in the fracture of composites, International Journal of Fracture 158: 211-223.

https://link.springer.com/article/10.1007\%2Fs10704009-9366-z.

8. Michigan Tech. 2016. Composite beam failure modes. http://www.mse.mtu.edu/ drjohn/my4150/sandwich/sp 1.html\#Table\%201.

9. ASTM D 907. 2015. Standard Terminology of Adhesives, ASTM International, West Conshohocken. https://www.scribd.com/document/385781777/E-90796-2004.

10. ASTM D 2093. 2017. Standard Practice for Preparation of Surfaces of Plastics Prior to Adhesive Bonding, ASTM International, West Conshohocken.

https://webstore.ansi.org/standards/astm/astmd2093032 017.

11. Standard ISO 291. 1998. Plastics - Standard atmospheres for conditioning and testing.

https://idoc.pub/documents/iso-291-wl12pkzpg54j.
12. Oasys LS-DYNA Environment. 2018. Introduction to Composites Modelling in LS-DYNA.

https://www.oasys-software.com/dyna/wpcotent/uploads/2019/03/6_Composites_Modelling_LSDYNA_Galal-Mohamed-IN.pdf.

13. Paiva, J. M. F.; Mayer, S.; Rezende, M. C. 2006. Comparison of tensile strength of different carbon fabric reinforced epoxy composites, Materials Research 9(1): 83-90.

http://www.scielo.br/scielo.php?script=sci_arttext\&pid $=$ S1516-14392006000100016.

14. Jiang, X. W.; Guo, S.; Li, H.; Wang, H. 2019. Peridynamic Modeling of Mode-I Delamination Growth in Double Cantilever Composite Beam Test: A TwoDimensional Modeling Using Revised Energy-Based Failure Criteria, Applied Sciences 9: 139-175. https://doi.org/10.3390/app9040656.

15. Hu, Y. L.; Madenci, E. 2016. Bond-based peridynamic modeling of composite laminates with arbitrary fiber orientation and stacking sequence, Composite Structures 153(1): 139-175.

https://doi.org/10.1016/j.compstruct.2016.05.063.

\section{T. Vaitkūnas, P. Griškevičius, K. Špakauskas}

\section{INTERLAMINAR FAILURE ANALYSIS OF BONDED CARBON FIBER RODS}

S u m m a r y

Interlaminar failure of bonded composite structures is quite often. Nowadays there is a lot of lightweight high reliability carbon or glass fiber (CFRP or GFRP) reinforced polymer composite constructions with bonded carbon or glass fiber rods. In order to better understand the delamination processes of the rods, analytical equations were analyzed. Later, mode I interlaminar failure experiments with CFRP rods $3 \times 3 \mathrm{~mm}$ were performed and fracture toughness $G_{I C}=135 \mathrm{~J} / \mathrm{m}^{2}$ was found. According to the analytic equations, experiment and values, given literature, finite element model (FEM) of the bonded carbon fiber rods was created in software $L S$-Dyna. Most of the differences between experimental and simulated forcedisplacement curves are not higher than $6 \%$ what validates the FEM of the bonded CFRP rods. Also, additional methods, such as peridynamics of the bond area of the rods were analyzed. Offered finite element approach of the bonded CFRP rods is very useful for FEM creation to design and evaluate high reliability CFRP or GFRP constructions.

Keywords: polymer matrix composites, interlaminar failure, fracture toughness, finite element model, peridynamics.

Received April 20, 2020 Accepted April 07, 2021

This article is an Open Access article distributed under the terms and conditions of the Creative Commons Attribution 4.0 (CC BY 4.0) License (http://creativecommons.org/licenses/by/4.0/). 